\title{
Orally administered penicillamine is a potent inhibitor of neointimal and medial thickening in porcine saphenous vein-carotid artery interposition grafts
}

Song Wan, FRCS, ${ }^{a}$ Nilima Shukla, PhD, ${ }^{\text {b }}$ Anthony P. C. Yim, FRCS, ${ }^{a}$ Jason L. Johnson, PhD, ${ }^{\text {b }}$ Gianni D. Angelini, FRCS, and Jamie $\mathrm{Y}$. Jeremy, $\mathrm{PhD}^{\mathrm{b}}$

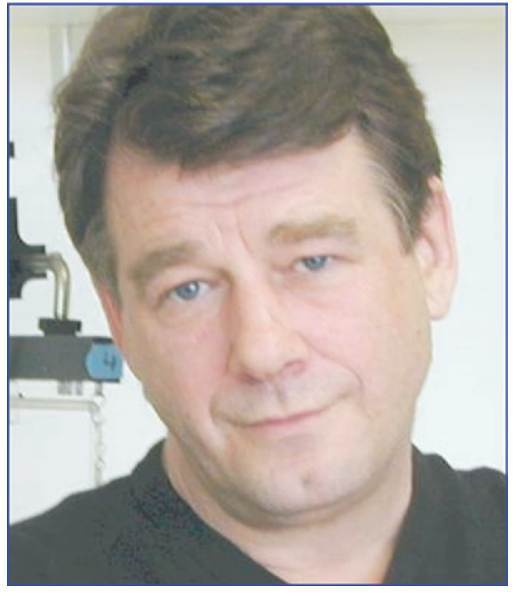

Dr Jeremy
From the Department of Surgery, Prince of Wales Hospital, Chinese University of Hong Kong, Hong Kong, China, ${ }^{a}$ and The Bristol Heart Institute, The University of Bristol, Bristol, UK. ${ }^{\mathrm{b}}$

Supported by the Chinese University of Hong Kong (CUHK 4310/99:CUHK 4091/ 00M).

Received for publication June 6, 2006; revisions received July 26, 2006; accepted for publication Aug 3, 2006.

Address for reprints: Jamie Y. Jeremy, $\mathrm{PhD}$, Bristol Heart Institute, Bristol Royal Infirmary, Bristol BS2 8HW (E-mail: j.y. jeremy@bristol.ac.uk).

J Thorac Cardiovasc Surg 2007;133:494-500 $0022-5223 / \$ 32.00$

Copyright () 2007 by The American Association for Thoracic Surgery

doi:10.1016/j.jtcvs.2006.08.071
Objective: In patients who have undergone coronary artery bypass grafting, blood copper levels are elevated for 6 weeks after surgery. Copper is an established risk factor for cardiovascular disease and atherogenesis and promotes oxidative stress, lipid oxidation, cell proliferation, and matrix formation, all components of vein graft disease. This project therefore examined the effect of the copper chelator penicillamine on saphenous vein graft thickening in a pig model.

Methods: Saphenous vein-carotid artery interposition grafts were carried out in Landrace pigs. Penicillamine $(10 \mathrm{mg} / \mathrm{kg}$ once daily, $\mathrm{n}=8)$ was administered orally incorporated into small amounts of mashed potato for 1 month ( $\mathrm{n}=8$ controls). Vein grafts were then excised and fixed at $100 \mathrm{~mm} \mathrm{Hg}$, histologic sections were prepared, and morphometry and measurement of proliferating cell nuclear antigen count were carried out. In vitro studies on the effect of copper or penicillamine on human vascular smooth muscle cell replication was carried out with bromodeoxyuridine incorporation.

Results: Administration of penicillamine had a potent inhibitory effect on both neointimal and medial thickness and proliferating cell nuclear antigen count but elicited a marked increase in luminal area and reduced serum copper concentrations. In vitro, copper augmented vascular smooth muscle cell proliferation, an effect blocked by penicillamine. Penicillamine alone also inhibited in vitro vascular smooth muscle cell replication.

Conclusion: The administration of penicillamine reduces vein graft thickening and promotes positive remodeling through negation of copper-induced cell proliferation. Copper chelators may therefore be therapeutically useful in preventing late vein graft failure in patients undergoing reconstructive arterial surgery.

$\mathrm{V}$ ein graft thickening with superimposed atherogenesis is the main cause of late failure after coronary artery bypass grafting (CABG) with autologous saphenous vein. ${ }^{1-3}$ Vein graft thickening is determined by increased medial thickening and neointimal formation, both of which involve the proliferation and migration of vascular smooth muscle cells (VSMCs). ${ }^{4}$ Superimposed on these rapid events is atherogenesis, which ultimately leads to graft occlusion in as many as $50 \%$ of cases within 10 years. ${ }^{1-3}$ Apart from aggressive lipid lowering therapy, ${ }^{5}$ there is no effective therapeutic intervention for late vein graft failure, ${ }^{4}$ which constitutes a considerable clinical problem in urgent need of resolution.

In patients who have undergone $\mathrm{CABG}$, blood copper levels are elevated for 6 weeks after surgery, probably from the concomitant and sustained increase in plasma ceruloplasmin. ${ }^{6}$ In turn, copper and ceruloplasmin are established risk factors for cardiovascular disease and atherogenesis. ${ }^{7,8}$ Copper possesses a number of activities that could promote vein graft disease. These include oxidative stress, 


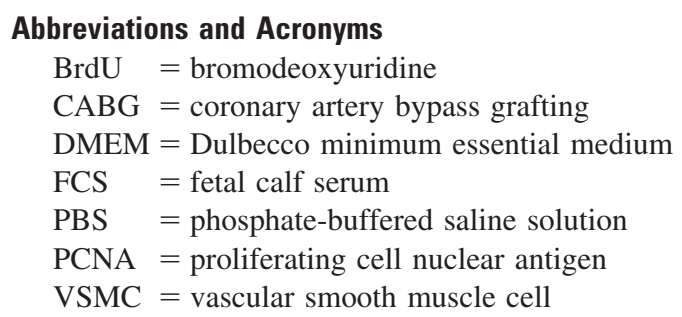

lipid oxidation, and promotion of cell proliferation and matrix formation and deposition. ${ }^{7,8}$ Other studies have demonstrated that copper promotes neointimal formation in animal models of arterial balloon injury and vascular inflammation. ${ }^{9,10}$

It is therefore reasonable to suggest that the increase in plasma copper after CABG may contribute to vein graft disease, including vein graft thickening. To test this proposal, the effect of oral administration of penicillamine on neointimal formation, medial thickening, and luminal area in saphenous vein-carotid artery interposition grafts 1 month after surgery were studied in a pig model. The dose of penicillamine used $(10 \mathrm{mg} / \mathrm{kg} \cdot \mathrm{d})$ was similar to that used to treat Wilson disease, systemic sclerosis, cysteine stones, and intractable rheumatoid arthritis. ${ }^{11-13}$ The study was offset by in vitro studies on the effect of copper alone and penicillamine on human VSMC replication.

\section{Materials and Methods}

Studies were performed with 16 Landrace pigs (8 control, 8 treated) weighing 30 to $35 \mathrm{~kg}$, all of which received humane care according to the Home Office Animals Care regulations. All animals underwent saphenous vein-carotid artery interposition grafting. ${ }^{14}$ Anesthesia was induced with ketamine $(30 \mathrm{mg}$ ) and atropine $(0.6 \mathrm{mg})$, administered intramuscularly. After endotracheal intubation, anesthesia was maintained with halothane, and oxygen and animals were allowed to breathe spontaneously throughout. Heparin sodium $(1 \mathrm{mg} / \mathrm{kg})$ was administered intravenously, and a single $250-\mathrm{mg}$ dose of benzyl penicillin was administered intramuscularly before skin incision. A longitudinal incision was made on the outer aspect of the hind limb. Approximately $10 \mathrm{~cm}$ of the vein was then dissected free of surrounding tissue with a "no touch" technique, and all side branches were secured with a 6-0 Prolene ligature (Ethicon Inc, Somerville, NJ). The vein was removed from the animal, rinsed in iso-osmotic sodium chloride solution $(0.9 \mathrm{~g} / \mathrm{L})$ containing $2-\mathrm{IU} / \mathrm{mL}$ heparin and $50-\mu \mathrm{g} / \mathrm{mL}$ glyceryl trinitrate, and stored in the same solution at room temperature $\left(23^{\circ} \mathrm{C}\right)$ until needed. A longitudinal neck incision was made just medial to the sternomastoid muscle, and the common carotid artery was carefully dissected from the internal jugular vein and vagus nerve within the carotid sheath. A 3-cm segment of the common carotid artery was isolated between vascular clamps and excised, beveling the cut ends obliquely to $45^{\circ}$. The saphenous vein was cut to the appropriate length, reversed, and similarly beveled, and an end-to-end anastomosis of the vein to the common carotid artery was carried out with a continuous 7-0 Prolene suture. Animals were extubated and, when in a satisfactory condition, returned to their pens and fed a normal diet.

Penicillamine (Sigma Chemical Co, Poole, UK) was given (10 $\mathrm{mg} / \mathrm{kg}$ once daily, $\mathrm{n}=8$ ) incorporated into small amounts of mashed potatoes to ensure complete ingestion of drugs. Controls consisted of another group of 8 pigs to whom potatoes without penicillamine were fed daily. Drug treatment was commenced 1 day before surgery. Animals were randomly allocated such that surgery was carried out alternately on control and then penicillaminetreated animals. After 4 weeks of daily administration of drugs, each animal was anesthetized, the neck wound was opened, and the graft was identified. Each graft was removed, including $1-\mathrm{cm}$ segments of the proximal and distal carotid arteries, pressure fixed ex vivo at $100 \mathrm{~mm} \mathrm{Hg}$ with Carson fixative, and postfixed in the same solution for approximately 24 hours before being processed for wax embedding. Sections were dewaxed, rehydrated, and stained with hematoxylin and eosin or Miller elastic van Gieson stain. For immunocytochemical testing, sections were dewaxed, rehydrated, and treated with hydrogen peroxide in methanol to remove endogenous peroxidase. For proliferating cell nuclear antigen (PCNA), sections were microwaved in citrate buffer, quenched in 1:3 horse serum in triethanolamine-buffered saline solution, and then incubated with PCNA antibody diluted 1:100 overnight at $4^{\circ} \mathrm{C}$. Sections were washed and then treated with 1:400 biotinylated goat antimouse antibody, followed by incubation with streptavidin, biotinylated horseradish peroxidase detection solution. Visualization was achieved with 3,3'-diaminobenzidine; after counterstaining with diluted hematoxylin and eosin, sections were dehydrated and mounted.

Vessel wall dimensions were measured by computer-aided planimetry with an Olympus BH-2 microscope with a color video camera head (JVC TK-870E; Olympus Optical Co, Ltd, Tokyo, Japan) coupled to a Microscale TM/TC image analysis system (Digithurst Ltd, Royston, UK). The area enclosed by the endothelium and the internal elastic lamina defined the intima, and the area between the internal and external elastic lamina defined the media. Luminal, intimal, and medial perimeters and areas were computed with the luminal boundary and internal and external elastic lamina as delimiters, and mean values were then calculated for all sections from the same graft. Average intimal, medial, and total vessel wall thicknesses were derived from the area and perimeter data for 5 sections from each graft, assuming that the sections consisted of circular profiles, which was valid assumption because the tissues were fixed at normal perfusion pressure.

At surgery, blood was collected from the ear vein. Plasma was prepared, and total copper concentrations were measured by the Department of Clinical Chemistry at the Bristol Royal Infirmary, as previously described. ${ }^{6}$

\section{Cell Proliferation Assay}

In vitro assays of human VSMC replication were carried out with bromodeoxyuridine (BrdU) incorporation as previously described. ${ }^{15}$ Saphenous veins were obtained from 6 patients undergoing $\mathrm{CABG}$ after ethical approval and patient consent were obtained. Veins were placed in Roswell Park Memorial Institute medium 164016 (Life Technologies Ltd, Paisley, United Kingdom) containing $2 \%$ amphotericin B (Life Technologies) and $0.4 \%$ 


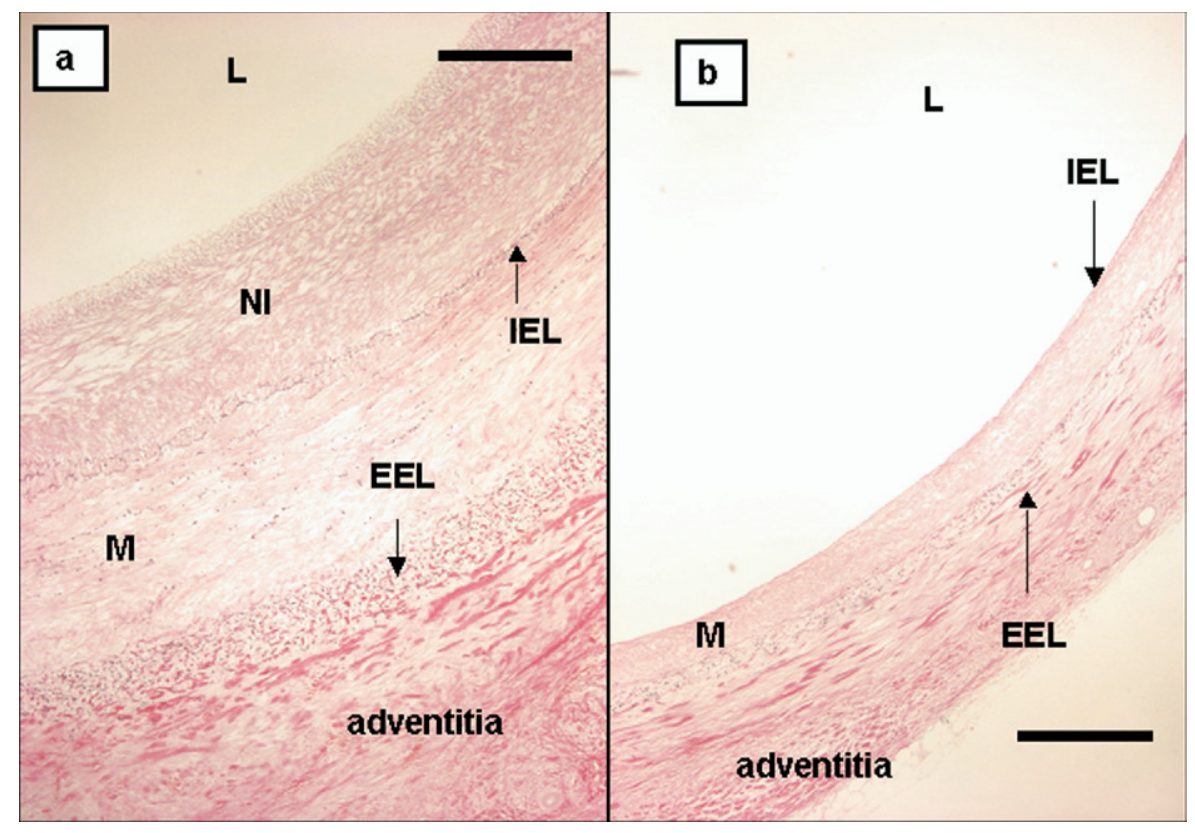

Figure 1. Representative photomicrographs 1 month after implantation of control saphenous vein graft (a) and saphenous vein graft from pig treated with penicillamine (b), demonstrating marked inhibition of graft thickening in treated pig. $L$, Lumen; IEL, internal elastic lamina; $N I$, neointima; $E E L$, external elastic lamina; $M$, media. Bar represents $100 \mu \mathrm{m}$.

heparin (Sigma). VSMCs were then grown in Dulbecco minimum essential medium-glutamax without sodium pyruvate (DMEM; Life Technologies) containing 100 units penicillamine (Sigma), $100-\mathrm{mg} / \mathrm{mL}$ streptomycin (Sigma), and 10\% fetal calf serum (FCS; DMEM-FCS; Life Technologies). After passage 4, human VSMCs were seeded onto 22-mm diameter coverslips in 12-well plates at a density of $6 \times 10^{4}$ cells/well and cultured for 48 hours in DMEM-FCS. Cells were rendered quiescent for 4 days in serumfree medium containing $0.25 \%$ lactalbumin hydrolysate (Life Technologies). Cells were then incubated with copper chloride or penicillamine and VSMCs incubated in DMEM-FCS containing $10-\mu \mathrm{mol} / \mathrm{L}$ bromodeoxyuridine (BrdU; Sigma) at $37^{\circ} \mathrm{C}$ in an oxygen/carbon dioxide (95\%:5\%) humidified incubator. After 48 hours, human VSMCs were fixed with $4 \%$ paraformaldehyde (weight/volume) in phosphate-buffered saline solution (PBS; Sigma), washed, and treated sequentially as follows with: (1) $3 \%$ hydrogen peroxide in methanol for 15 minutes at $4^{\circ} \mathrm{C}$, (2) $2-\mathrm{N}$ hydrochloric acid for 30 minutes at $37^{\circ} \mathrm{C}$, and (3) $0.1 \%$ Triton-X (The Dow Chemical Company, Midland, Mich) for 10 minutes at $25^{\circ} \mathrm{C}$, cells being washed with PBS between each step (all chemicals from Sigma). Cells were then incubated with a monoclonal primary antibody against $\mathrm{BrdU}$ (ICN, Basingstoke, UK) at 1:10 in $3 \%$ (weight/volume) bovine serum albumin/normal horse serum/ PBS for 2 hours at $37^{\circ} \mathrm{C}$. Incubation with biotinylated secondary antibody (ICN) diluted 1:200 in 3\% bovine serum albumin in PBS (Sigma) was carried out for 45 minutes at $25^{\circ} \mathrm{C}$. Cells were then incubated with horseradish peroxidase-conjugated ExtraAvidin (Sigma) diluted 1:200 in 3\% bovine serum albumin/PBS, also for 45 minutes at $25^{\circ} \mathrm{C}$. Positive nuclei were developed by incubation of cells with $0.05 \%$ 3,3-diaminobenzidine (Sigma)/0.03\% hydrogen peroxide in $\mathrm{PBS}$ at $25^{\circ} \mathrm{C}$ for 10 minutes. Negative nuclei were counterstained with hematoxylin (Sigma). Dehydrations of cells through ethanol and Histo-Clear (National Diagnostics USA, Atlanta, Ga) were performed, and cells were mounted in 1,3- diethyl-8-phenylxanthine. Five fields from each sample were counted at $\times 20$ magnification, and the percentage of cells positive for BrdU was calculated.

\section{Data Analysis and Statistics}

Data were collated and analyzed with Microsoft Excel (Microsoft Corporation, Redmond, Wash), and nonparametric statistical analysis was carried out with an Intercooled Stata 8 statistics package (Stata Corporation, College Station, Tex). The Barlett test for equality of variance (a necessary assumption for a 1-way analysis of variance) was significant, indicating that nonparametric methods of analysis was required for morphometric appraisal of vein grafts, PCNA, and total plasma copper. Thus values are expressed as median and 25th and 75th interquartile ranges and graphically as box and whisker plots. Mann-Whitney $U$ tests were then applied to test the statistical significance of differences between control and treated groups. In contrast, in vitro data were parametric. Data are therefore expressed as mean $\pm \operatorname{SEM}(n=6)$, and statistical comparisons were performed with unpaired Student $t$ tests.

\section{Results}

All grafts were patent 4 weeks after implantation. There were significant increases in the luminal area, neointimal thickness, medial thickness, and medial area in vein grafts from untreated animals relative to ungrafted saphenous veins (Figures 1-4). Administration of penicillamine elicited a potent inhibitory effect on neointimal thickness and area (Figure 2) and on medial thickness and area (Figure 3) but promoted a marked increase in luminal area relative to controls (Figure 4). The administration of penicillamine also had a significant inhibitory effect on PCNA count, 


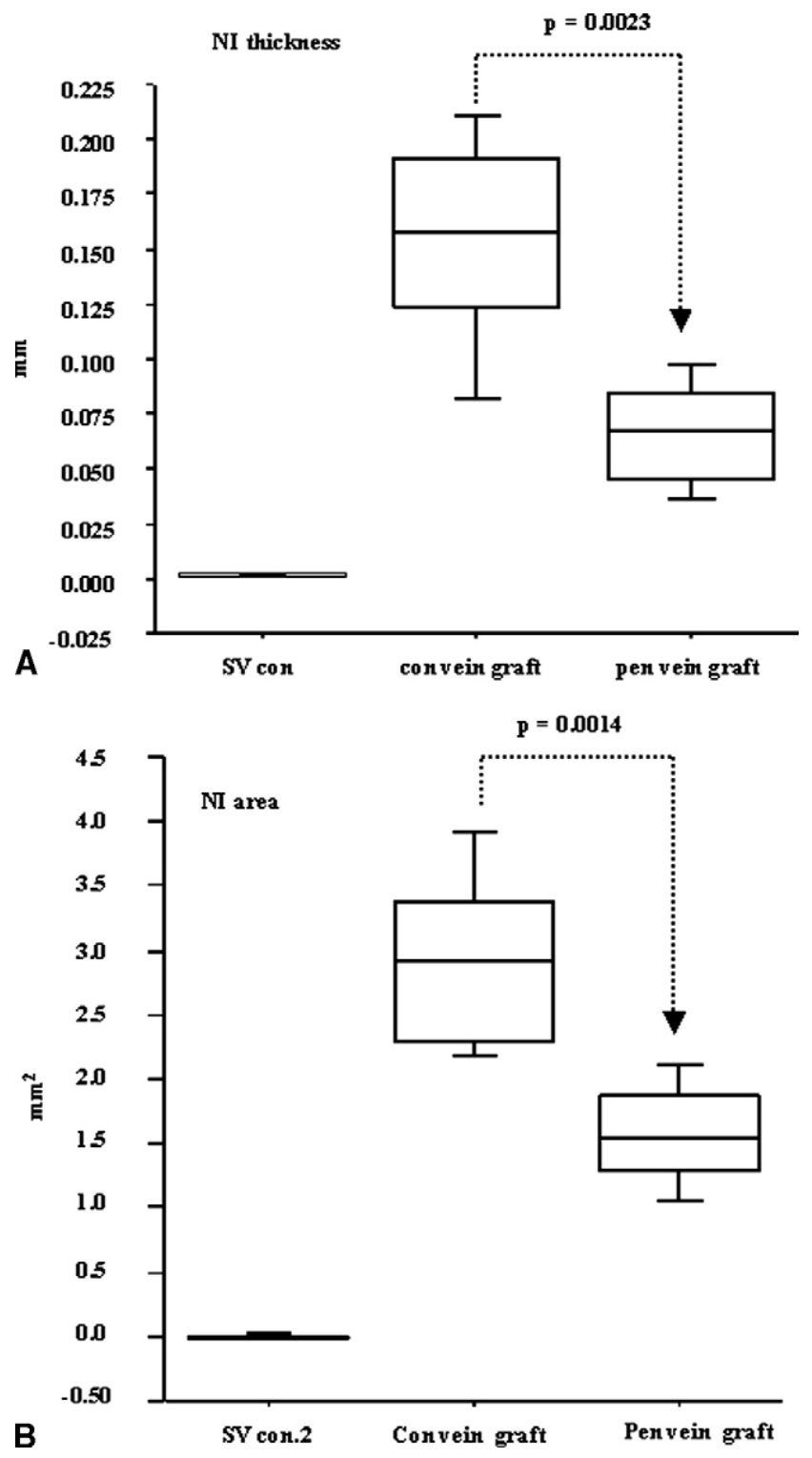

Figure 2. Comparison of neointimal (NI) thickness (A) and area (B) between vein grafts from pigs to whom penicillamine was administered orally at $10 \mathrm{mg} / \mathrm{kg}$ once daily for 4 weeks (pen vein graft) relative to controls (con vein graft). Data are expressed as medians and 25th and 75th interquartile ranges, $n=8$. $S V$ con, $S V$ con.2, Ungrafted saphenous vein.

reducing it from 21.1 (19.9-23.0) in controls to 12.5 (11.413.2, $P=.0018)$ in pigs treated with penicillamine, and significantly reduced serum copper levels from $12.6 \mu \mathrm{mol} / \mathrm{L}$ (12.5-12.8 $\mu \mathrm{mol} / \mathrm{L})$ to $9.6 \mu \mathrm{mol} / \mathrm{L}(9.3-10.2 \mu \mathrm{mol} / \mathrm{L}, P<$ $.01)$. In the in vitro studies, copper at nanomolar to low micromolar concentrations augmented VSMC proliferation in a concentration-dependent manner, as assessed by BrdU incorporation, an effect blocked by penicillamine (Figure 5),

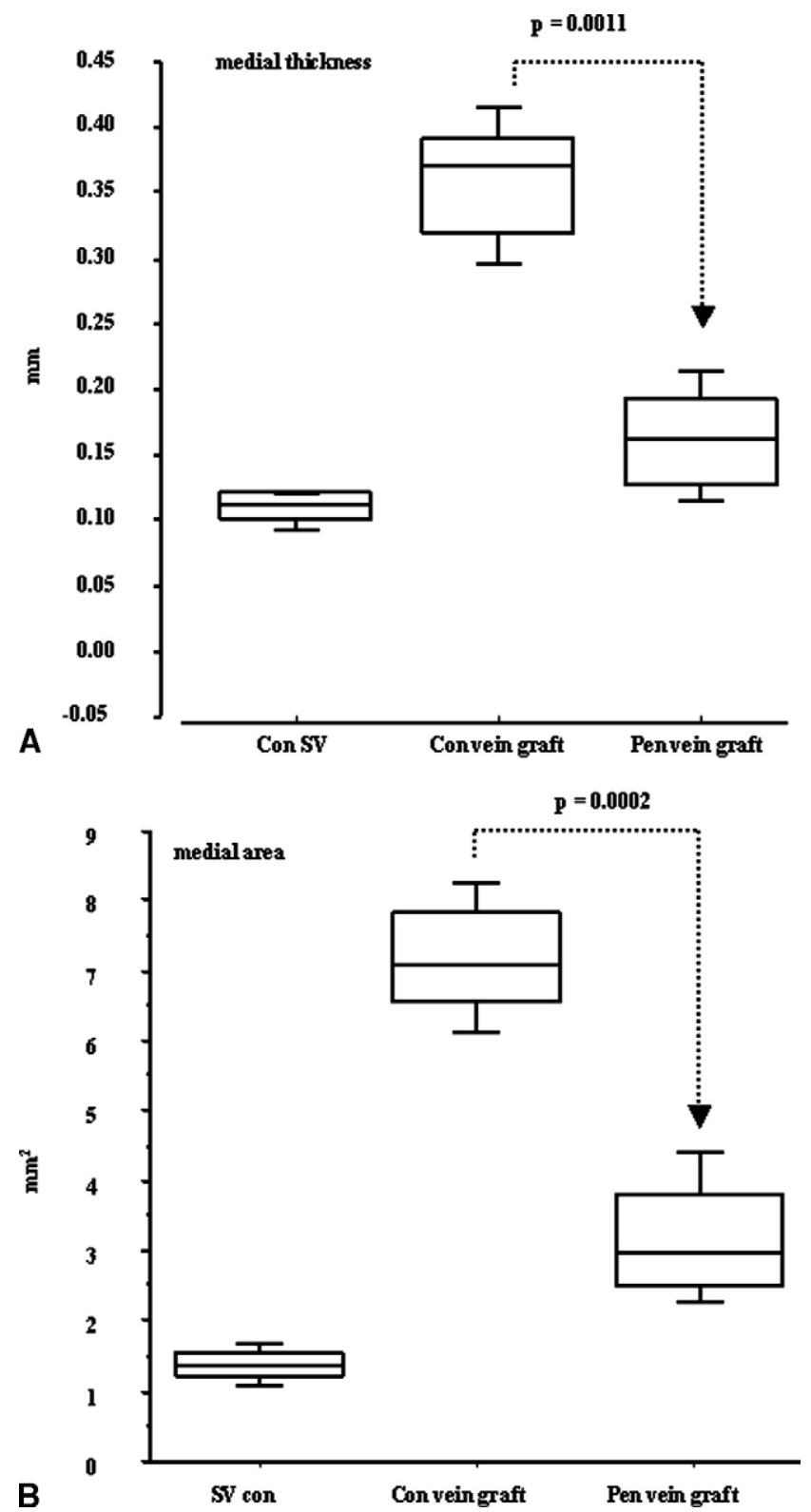

Figure 3. Comparison of medial thickness (A) and area (B) between vein from pigs to whom penicillamine was administered orally at $10 \mathrm{mg} / \mathrm{kg}$ once daily for 4 weeks (pen vein graft) relative to controls (con vein graft). Data are expressed as medians and 25th and 75th interquartile ranges, $n=8$. Con SV, SVcon, Ungrafted saphenous vein.

confirming that penicillamine does in fact chelate copper. Penicillamine alone also inhibited in vitro VSMC replication stimulated with serum (Figure 6).

\section{Discussion}

This study clearly demonstrates that orally administered penicillamine is a potent inhibitor of neointimal formation 


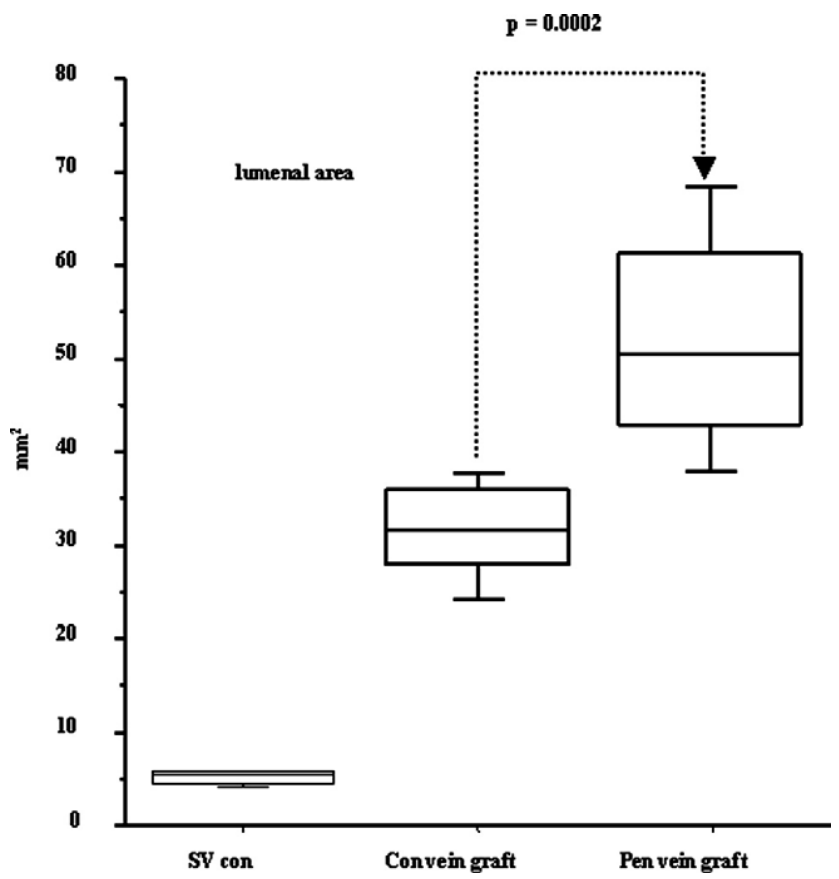

Figure 4. Planimetric analysis of luminal area between vein grafts from pigs to whom penicillamine was administered orally at $10 \mathrm{mg} / \mathrm{kg}$ once daily for 4 weeks (pen vein graft) relative to controls (con vein graft). Data are expressed as medians and 25th and 75th interquartile ranges, $n=8$. $S V$ con, Ungrafted saphenous vein.

and medial thickness but increases luminal area in porcine saphenous vein-carotid artery interposition grafts. This effect was associated with a marked reduction of intragraft proliferating cells. Circulating plasma copper levels were significantly reduced by penicillamine administration, indicating that the effects were mediated by a reduction of plasma copper. Furthermore, in vitro studies demonstrated that copper alone promotes VSMC proliferation and that penicillamine blocks this effect. The inhibition of proliferation by penicillamine indicates that endogenous intragraft copper may in itself elicit increased VSMC proliferation. These data are consistent with previous studies of the oral administration of tetrathiomolybdate, another copper chelator, in which it was demonstrated that this agent reduced neointimal thickening after balloon injury in the rat $^{9}$ and, more recently, that it inhibited in-stent restenosis in porcine coronary arteries. ${ }^{17}$ Other studies have demonstrated that other copper chelators inhibit cell proliferation in vitro. ${ }^{18,19}$ The corollary to this is that copper induces inflammatory reactions and elicits stenosis and neointimal formation in animal models of vascular inflammation. ${ }^{10,20}$

Another facet of the study was that penicillamine administration resulted in a marked enlargement of luminal area, which may be indicative of an inhibitory effect on the

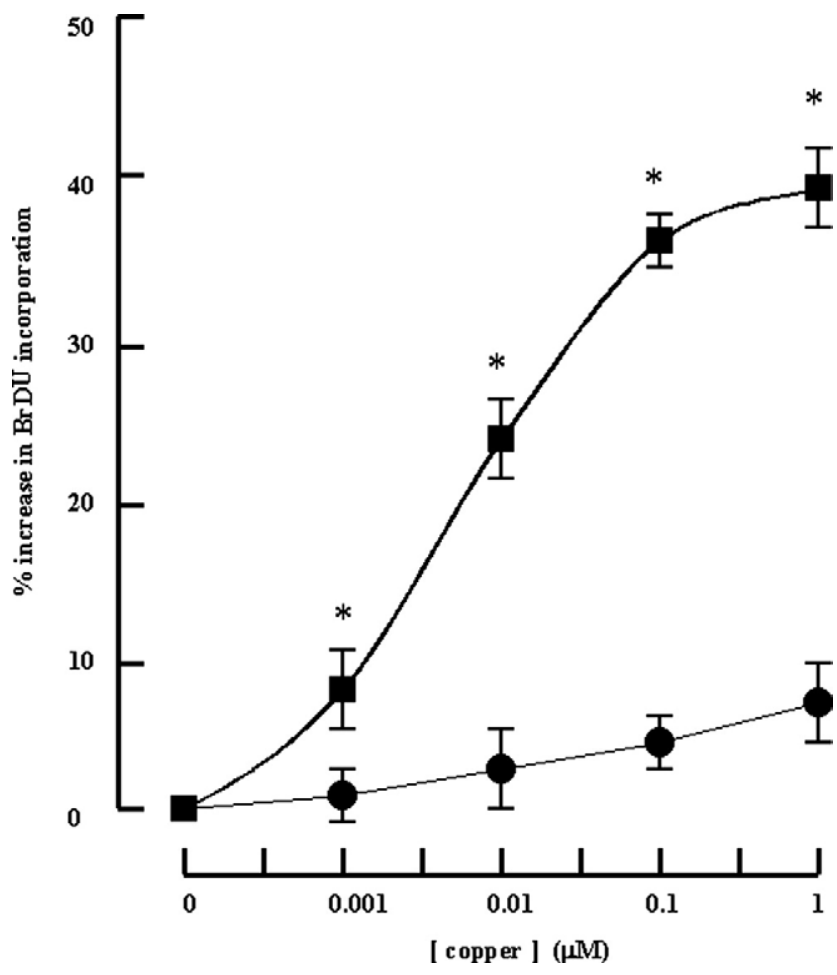

Figure 5. Effect of copper chloride $(\square)$ and copper chloride with 100-nmol/L penicillamine (O) on bromodeoxyuridine (BrdU) incorporation (index of cell replication) into human VSMCs after stimulation with $10 \%$ fetal calf serum (percentage cells positive for BrdU staining relative to zero controls) assessed 48 hours after stimulation. Each point represents mean $\pm S E M, n=6$. Asterisk indicates $\boldsymbol{P}<.001$ relative to zero controls.

deposition of matrix proteins. Copper plays an axiomatic role in mediating lysyl oxidase, ${ }^{21}$ an enzyme that controls the cross-linking of collagen, an important matrix protein. In turn, vein graft thickening is characterized by increased collagen deposition, which is mediated by complex interactions between matrix metalloproteinases and growth factors. $^{22}$ It is therefore tempting to speculate that copper chelators may influence this deposition of collagen through inhibition of lysyl oxidase, which in turn would explain the marked positive remodeling elicited by penicillamine in this study.

Under normal circumstances, copper is tightly bound to plasma proteins, in particular ceruloplasmin. ${ }^{7,8}$ Several of the coppers bound to ceruloplasmin are exchangeable (chelatable), which is crucial because copper is transported in the blood by ceruloplasmin and taken up by tissues from ceruloplasmin through a complex chaperone system. ${ }^{23} \mathrm{Re}-$ active oxygen species, however, including superoxide, peroxynitrite, and hydrogen peroxide, dissociate copper from its protein binding sites on ceruloplasmin and to fragment 


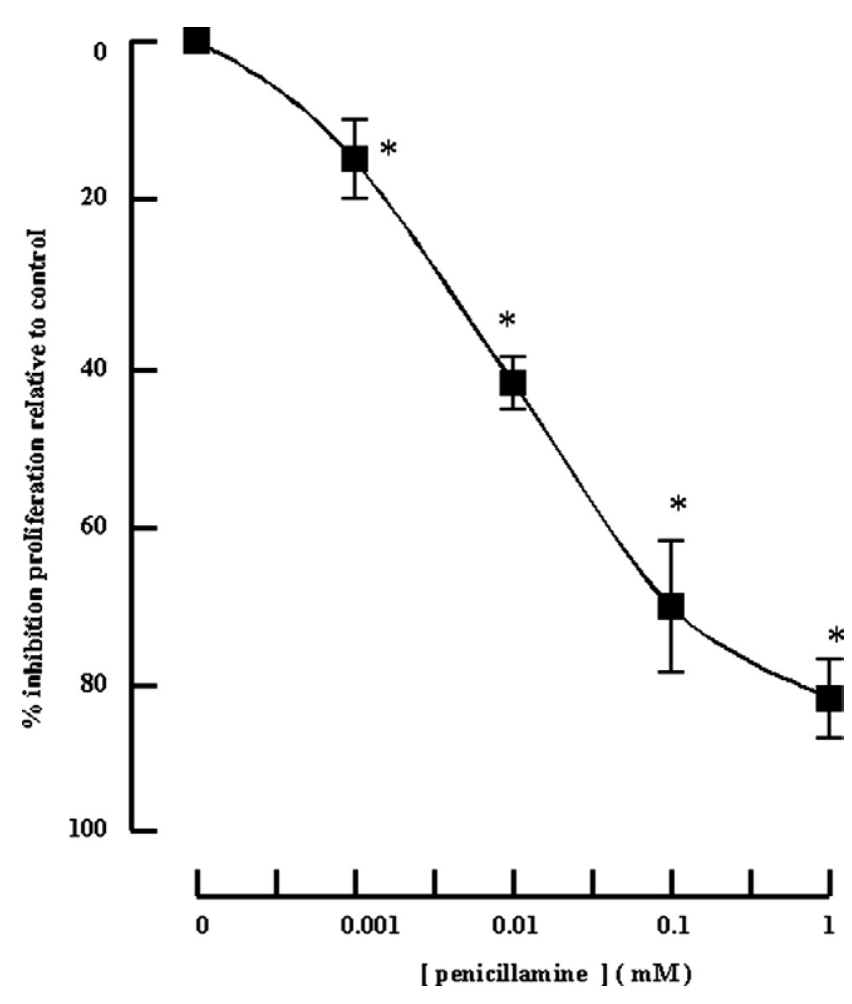

Figure 6. Effect of penicillamine on bromodeoxyuridine incorporation (index of cell replication) into human VSMCs after stimulation with $10 \%$ fetal calf serum (percentage of cells positive for bromodeoxyuridine staining relative to zero controls) assessed 48 hours after stimulation. Each point represents mean $\pm S E M, n=$ 6. Asterisk indicates $\boldsymbol{P}<.001$ relative to zero controls.

the protein. ${ }^{24-26}$ In turn, free copper may augment the vasculopathic effects demonstrated here. In this context, vein grafts are associated with increased intragraft oxidative stress. ${ }^{27,28}$ It is therefore reasonable to speculate that increased ceruloplasmin and copper levels, coupled with increased reactive oxygen species formation, may result in the local release of free copper, which in turn exerts vasculopathic effects on the vein grafts and that chelation of this copper by penicillamine may account for the emphatic results obtained here.

In support of this proposal, penicillamine administration prevents intravascular oxidative stress, including a reduction of superoxide formation and restoration of impaired nitric oxide formation, in arteries of hyperhomocysteinemic rabbits. ${ }^{29}$ This is of direct relevance for several reasons. In patients undergoing CABG, plasma homocysteine is also elevated, ${ }^{6}$ along with ceruloplasmin and copper, and it remains so for at least 5 weeks after surgery. Homocysteine is a risk factor for vein graft failure. ${ }^{30,31}$ Several studies have demonstrated that copper and homocysteine interact to promote a vasculopathic pathway, including the oxidation of low-density lipoprotein and vascular cell damage. ${ }^{32,33}$ Copper augments the formation of superoxide from homocysteine by virtue of transition metal interactions with the thiol moiety of homocysteine through Fenton and Haber-Weiss type reactions. ${ }^{8}$

From a therapeutic perspective, penicillamine is used to treat Wilson disease, systemic sclerosis, cysteine stones, and intractable rheumatoid arthritis. ${ }^{9,11}$ Another copper chelator, thiomolybdate, has proved effective in reducing inflammation and has been purported to exert less serious side effects than other chelators. ${ }^{34}$ Although it remains to be determined whether this effect of penicillamine persists over the longer term, the drug is likely to suppress neointimal formation and medial thickening as long as it is being continually administered. It would be of interest, however, to determine whether cessation of therapy (at 1 month) leads to a reversal of effects over the longer term (3-6 months). This warrants study. Clinical trials aimed at studying the effect of copper chelators on late vein graft failure in patients undergoing reconstructive arterial surgery also warrant consideration. ${ }^{16}$

\section{References}

1. Fitzgibbon GM, Kafka HP, Leach AJ, Keon WJ, Hooper GD, Burton JR. Coronary bypass graft fate and patient outcome: angiographic follow-up of 5,065 grafts related to survival and re-operation in 1,388 patients during 25 years. J Am Coll Cardiol. 1999;28:616-26.

2. Favaloro RG. Critical analysis of coronary artery bypass graft surgery: a 30-year journey. J Am Coll Cardiol. 1998;31(4 Suppl B):1B-63B.

3. Mortwani JG, Topol EJ. Aortocoronary saphenous vein graft disease. Pathogenesis, predisposition and prevention. Circulation. 1998;97: 916-31.

4. Davies MG, Hagen PO. Pathobiology of intimal hyperplasia. $\mathrm{Br} J$ Surg. 1995;81:1254-69.

5. Campeau L. Lipid lowering and coronary bypass graft surgery. Curr Opin Cardiol. 2000;15:395-9.

6. Jeremy JY, Shukla N, Angelini GD, Wan I, Talpahewa SP, Ascione R. Sustained increases in homocysteine, copper and ceruloplasmin following coronary artery bypass grafting. Ann Thorac Surg. 2002;74: 1553-7.

7. Fox PL, Mazumder B, Ehrenwald E. Ceruloplasmin and cardiovascular disease. Free Radic Biol Med. 2000;28:1735-44.

8. Shukla N, Maher J, Masters J, Angelini GD, Jeremy JY. Does oxidative stress change ceruloplasmin from a protective to a vasculopathic risk factor? Atherosclerosis. 2006;187:238-50.

9. Mandinov L, Mandinova A, Kyurkchiev S, Kyurkchiev D, Kehayov I, Kolev V, et al. Copper chelation represses the vascular response to injury. Proc Natl Acad Sci U S A. 2003;100:6700-5.

10. Volker W, Dorszewski A, Unruh V, Robenek H, Bretihardt G, Buddecke E. Copper-induced inflammatory reactions of rat carotid arteries mimic restenosis/arteriosclerosis-like neointima formation. Atherosclerosis. 1997;130:29-36.

11. Clements PJ, Seibold JR, Furst DE, Mayes M, White B, Wigley F, et al. High-dose versus low-dose D-penicillamine in early diffuse systemic sclerosis trial: lessons learned. Semin Arthritis Rheum. 2004; 33:249-63.

12. Martins da Costa C, Baldwin D, Portmann B, Lolin Y, Mowat AP, Mieli-Vergani G. Value of urinary copper excretion after penicillamine challenge in the diagnosis of Wilson's disease. Hepatology. 1992;15:609-15.

13. Ogihara H, Ogihara T, Miki M, Yasuda H, Mino M. Plasma copper and antioxidant status in Wilson's disease. Pediatr Res. 1995;37:219-26.

14. Wan S, Yim A, Bulbulia RA, Johnson JL, Smith FC, Angelini GD, et al. The endothelin 1A receptor antagonist BSF 302146 is a potent 
inhibitor of porcine vein graft thickening in vivo. J Thorac Cardiovasc Surg. 2004; 127:1317-22.

15. Shukla N, Rowe D, Hinton J, Angelini GD, Jeremy JY. Calcium and the replication of human vascular smooth muscle cells: studies on the translocation of extracellular signal regulated kinase (ERK and cyclin D1 expression). Eur J Pharmacol. 2005;509:21-30.

16. Freshney RI. Culture of animal cells: a manual of basic techniques. 3rd ed. New York: John Wiley \& Sons; 1993. p. 48.

17. Mandinov L, Moodie KL, Mandinova A, Zhuang Z, Redican F, Baklanova D, et al. Inhibition of in-stent restenosis by oral copper chelation in porcine coronary arteries. Am J Physiol Heart Circ Physiol. 2006;291:H2692-7.

18. Moon SK, Jung SY, Choi YH, Lee YC, Patterson C, Kim CH. PDTC, metal chelating compound, induces G1 phase cell cycle arrest in vascular smooth muscle cells through inducing p21Cip1 expression: involvement of p38 mitogen activated protein kinase. Cell Physiol. 2004;198:310-23.

19. Pan Q, Bao LW, Merajver SD. Tetrathiomolybdate inhibits angiogenesis and metastasis through suppression of the $\mathrm{NF} \kappa \mathrm{B}$ signaling cascade. Mol Cancer Res. 2003;1:701-6.

20. Popilis VA, Cornelissen I, Sandoval-Copper MJ, Weeks L, Noria FA, Castellino FJ. Remodeling of the vessel wall after copper-induced injury is highly attenuated in mice with a total deficiency of plasminogen activator inhibitor-1. Am J Pathol. 2001;158:107-17.

21. Rucker RB, Kosonen T, Clegg MS, Mitchell AE, Rucker BR, UriuHare JY, et al. Copper, lysyl oxidase, and extracellular matrix protein cross-linking. Am J Clin Nutr. 1998;67(5 Suppl):996S-1002S.

22. Newby AC. Dual role of matrix metalloproteinases (matrixins) in intimal thickening and atherosclerotic plaque rupture. Physiol Rev. 2005;85:1-31.

23. Field LS, Luk E, Culotta VC. Copper chaperones: personal escorts for metal ions. J Bioenerg Biomembr. 2002;34:373-9.

24. Choi SY, Kwon HY, Kwon OB, Eum WS, Kang JH. Fragmentation of human ceruloplasmin induced by hydrogen peroxide. Biochimie. 2000; 82:175-80.
25. Musci G, Fraterrigo TZ, Calabrese L, McMillin DR. On the lability and functional significance of the type I copper pool in ceruloplasmin. J Biol Inorg Chem. 1999;4:441-6.

26. Kang JH, Kim KS, Choi SY, Kwon HY, Won MH. Oxidative modification of human ceruloplasmin by peroxyl radicals. Biochim Biophys Acta. 2001;1568:30-6.

27. Jeremy JY, Shukla N, Muzaffar S, Angelin GD. Reactive oxygen species, vascular disease and cardiovascular surgery. Curr Vasc Pharmacol. 2004;2:229-36.

28. Jeremy JY, Yim AP, Wan S, Angelini GD. Oxidative stress, nitric oxide and vascular disease. Cardiovasc Surg. 2002;17:324-7.

29. Shukla N, Koupparis A, Jones RA, Persad R, Angelini GD, Jeremy JY. Penicillamine administration reverses the inhibitory effect of hyperhomocysteinaemia on endothelium-dependent relaxation and superoxide formation in the aorta of the rabbit. Eur J Pharmacol. 2006;531: 201-8.

30. Iwama Y, Mokuno H, Yokoi H, Daida H, Yamaguchi H, Hosoda Y. [Elevated levels of plasma homocysteine related to saphenous vein graft disease after coronary artery bypass graft surgery.] Japanese. J Cardiol. 1998;32:357-62.

31. Irvine C, Wilson YG, Currie IC, McGrath C, Scott J, Day A, et al. Hyperhomocysteinaemia is a risk factor for vein graft stenosis. Eur $J$ Vasc Endovasc Surg. 1996;12:304-9.

32. Burkitt J. A critical overview of the chemistry of copper-dependent low density lipoprotein oxidation: roles of lipid hydroperoxides, alphatocopherol, thiols, and ceruloplasmin. Arch Biochem Biophys. 2001; 394:117-35.

33. Hultberg B, Andersson A, Isaksson A. The cell-damaging effects of low amounts of homocysteine and copper ions in human cell line cultures are caused by oxidative stress. Toxicology. 1997;21:33-40

34. Brewer GJ. Tetrathiomolybdate anticopper therapy for Wilson's disease inhibits angiogenesis, fibrosis and inflammation. J Cell Mol Med. 2003;7:11-20. 